\title{
SIMULATION AND EXPERIMENTAL STUDIES FOR LATERAL EXTRUSION OF SQUARE AND PENTAGONAL HEAD FROM ROUND SHAFT
}

\author{
Umesh Chandra Paltasingh ${ }^{1}$, Susanta Kumar Sahoo ${ }^{2}$, Pusparaj Dash ${ }^{3}$, Kanhu Charan Nayak ${ }^{4}$ \\ ${ }^{1}$ Ph.D Scholar, Mechanical Engg. Department, Padmanav College of Engg, Odisha, India, ucpaltasingh69@gmail.com \\ ${ }^{2}$ Professor, Mechanical Engg. Department, NIT Rourkela, Odisha, India, sks@nitrkl.ac.in \\ ${ }^{3}$ Professor. Mechanical Engg. Department, VSSUT Burla, Odisha, India, prdash_india@yahoo.co.in \\ ${ }^{4}$ M.Tech Scholar, Mechanical Engg. Department, Institute Name, State, Country, nayakkanhu83@gmail.com
}

\begin{abstract}
Recently, in different industries a surging trend has been observed in the demand of integral parts instead of assembled parts due to their increased strength. The components from lateral extrusion process are suitable for this purpose. Variations in load and flow direction of metal are greatly affected by the extruded geometry in this process. Keeping in view the above factors as an objective, an experimental die-punch set-up for lateral extrusion is designed and the process is simulated using finite element method both for estimation of load requirement and metal flow patterns. Experimental studies have been carried out to find the extrusion load and the direction of metal flow at different die geometry, taking lead as the billet material. The predictions both in extrusion load and the deformed configuration are in good agreement with the experiment qualitatively under different geometry conditions. Progressive flow of metal at different die geometry has also been studied.
\end{abstract}

Index Terms: Die-punch, Finite element analysis, Forming load, Lateral extrusion, Metal flow pattern

\section{INTRODUCTION}

Extrusion is one of the metals forming process that has a large area of applications. There are four basic types of extrusion: direct (forward), indirect (backward), hydrostatic, and impact. Irrespective of above mentioned types, there is another type of extrusion called radial extrusion. The radial extrusion also termed as lateral extrusion or sideway extrusion is an important branch of the extrusion process in which the cylindrical solid or tubular billet contained in the chamber is pressed by one or two opposite simple punches, causing the radial material flow through a fixed die cavity [1]. It is a special upset forging, where the flow direction of material is perpendicular to the punch movement.

This process is a high speed production process which has an advantage of being economical relative to other production processes. The machine components with complex flange geometry or segmented protrusions such as gears and splines, which are very difficult to produce by the conventional forging, can be easily produced by the above method. It has several advantages, such as minimum material waste, high dimensional accuracy, reduction or complete elimination of machining, good surface finish, better mechanical properties of products, less load requirements, comparing to close die forging in productions of parts with radial geometries[1]. A study about metal flow in lateral extrusion mostly covers simple shaped flanges. Balendra [2-5] has studied effects of process parameters on metal flow and load requirements for complete flanges. The importance of analyses for the extrusion process lies in the determination of forming load, flow characteristics, temperature and state of stress and strain [6]. Balendra and Qin [7-9] have studied effects of process parameters on material flow and load requirement for complete flanges. They have defined an aspect ratio of primary deformation zone (the ratio of gap height $\mathrm{s}$, to billet initial diameter $\mathrm{d}, \mathrm{T}=\mathrm{s} / \mathrm{d}$ ) for complete flanged part produced by using this method. The results obtained by their studies show that when $\mathrm{T}<0.8$ acceptable material flow can be obtained but required forming force increase since metal flows into narrow die gap. Lee et al. [10] and Choi et al. [11] studied the effect of punch diameter and the friction factor on the forming load by the finite element method (FEM). Patra and Sahoo [12] carried the series of experiments for the extrusion forging of pentagonal head with round shaft and analyzed the results for steady state peak load. In the previous work the lateral extrusion of round to triangular head are discussed for various thicknesses and compared the peak loads between FE and experimental results [13]. Since the forming loads depend upon the cross-section of die profile [14] therefore it becomes necessary to carry out more experiments on lateral extrusion of square and pentagonal headed dies. 
In the present investigation experimental studies are carried out with a view to compare some of the experimental results of more than one shape with FEM using DEFORM-3D model. Experiments of lateral extrusion are performed for square and pentagon sections using three flat dies each of respective shapes of varying thickness and cross-section. Commercially available tellurium lead is used as the working material. An extrusion test rig is designed and developed on thumb rule basis for the said purpose and all extrusions are carried out using round billets.

\section{SIMULATION PROCEDURE FOR FINITE ELEMENT ANALYSIS}

An implicit and static finite element model DEFORM-3D® is adopted to analyze the plastic flow pattern of the billet within the die cavity during lateral extrusion of a square and pentagonal headed section with varying thickness and crosssection. The finite element code is based on the flow formulation approach using an updated Lagrange procedure. During the simulations, it is assumed that the billet is rigid plastic, and the die, the container as well as the flow guide are all rigid. The interfaces between the billet and the die, container, and the flow guide have a constant friction factor $\mathrm{m}$, which is set to be 0.21 to correspond to the condition of cold forming. The four-node tetrahedron elements are used. The billet is divided into about 30,000 elements. In order to reduce the simulation time, the die cavity is filled with the billet before extrusion. The temperatures of all the objects are set as $30{ }^{\circ} \mathrm{C}$. The isothermal condition is adopted in the finite element simulations. The iteration methods adopted for solving the nonlinear equations are the Newton-Raphson and the direct iteration methods. The direct iteration method is used to generate a good initial guess for the Newton-Raphson method, whereas the Newton-Raphson method is used for speedy final convergence. When the plastic deformation reaches the steady state, the simulation is stopped. The diameter of the billet is 30 $\mathrm{mm}$. The ram speed is $1 \mathrm{~mm} / \mathrm{min}$. The database of flow stress for lead billet at $30^{\circ} \mathrm{C}$ in is used for the simulation.

The three dimensional finite element analyses has been used to investigate the effect of some important geometrical parameters such as initial billet diameter and height, volume of die cavity as well as process condition such as friction in the process.

\section{EXPERIMENTAL ANALYSIS}

\subsection{The test rig}

The series of experiments are conducted on a 600T hydraulic press with constant ram speed of $1 \mathrm{~mm} / \mathrm{min}$. The test rig mainly consists of five parts namely, the container having a cylindrical extrusion chamber of $30 \mathrm{~mm}$ diameter, the extruding punch of same diameter, the die holder, lateral extrusion dies at different cross-section and thickness, and the supporting block for the die holder. A schematic diagram of experimental setup with test rig and the die assembly has been shown in Fig. 1.The diameter and height of container is taken as $140 \mathrm{~mm}$ and $120 \mathrm{~mm}$ respectively. The punch length is $120 \mathrm{~mm}$. The die assembly consists of a die holder of outer diameter $140 \mathrm{~mm}$, inner diameter $80 \mathrm{~mm}$ and thickness $20 \mathrm{~mm}$ with split dies of same inner diameter and thickness. Two flat plates of $5 \mathrm{~mm}$ thick and profile same as that of the die are used to reduce the die thickness to subsequently $15 \mathrm{~mm}$ and $10 \mathrm{~mm}$ (Fig. 2 (b)). The die holder was made from high carbon steel round block by shaping. There is a base plate of same diameter as that of the outer diameter of the container and thickness $10 \mathrm{~mm}$ with $4 \mathrm{nos}$ of bolt holes of $\phi 12 \mathrm{~mm}$ which support both extrusion chamber and die holder. Both extrusion chamber and die holder are fastened together rigidly by four hexagonal headed Allen HT bolts of $\phi 12 \mathrm{~mm}$. The commercial lead billets of $\phi 32 \mathrm{~mm}$ were casted and machined to the required diameter of $\phi 30 \mathrm{~mm}$. The inside surfaces of the extrusion chamber are flame hardened to reduce frictional wear.

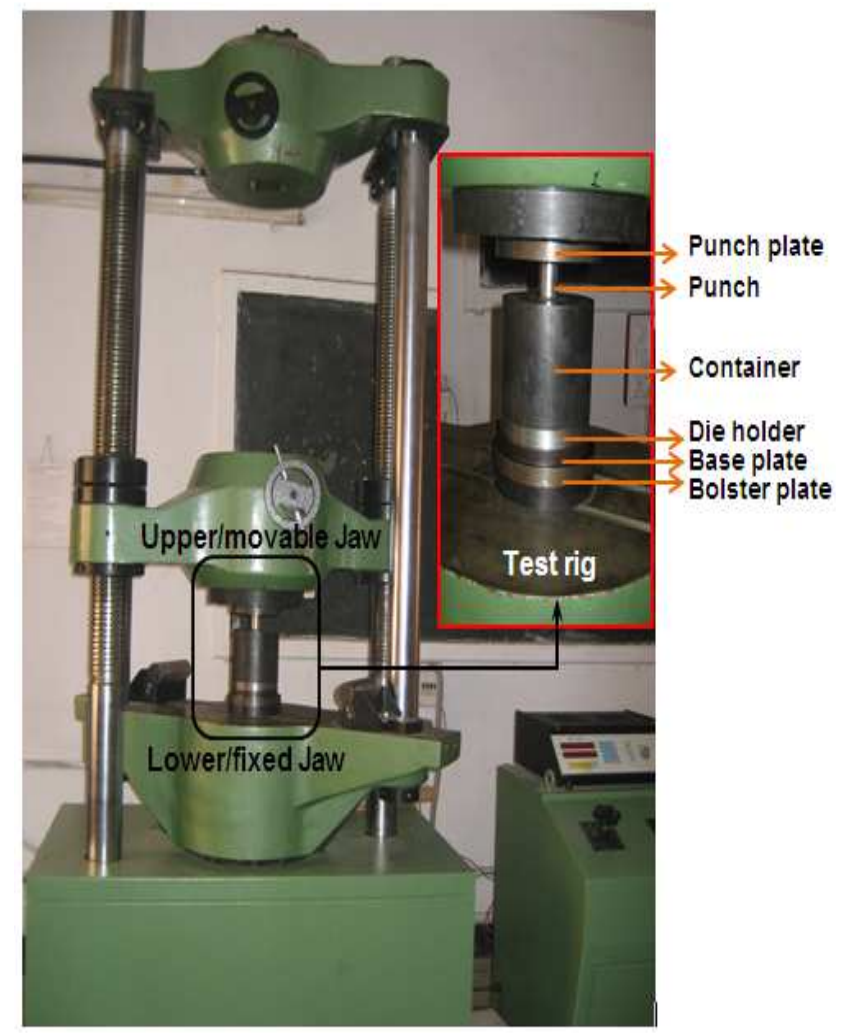

Fig-1: Photographic view of experimental set up with test rig

\subsection{Flat dies}

The flat dies used in the present series of experiments are made of two split halves for easy removal of the extruded product as shown in Fig. 2(a). The orifices are so made that the respective centers of gravity lie on the billet axis. These dies are produced by wire cut EDM from $20 \mathrm{~mm}$ thick flat 
plates oil- hardened and non-shrinking EN31 hot rolled tool steel. After machining, each die set is first normalized at a temperature of $9300 \mathrm{C}$ in a reducing atmosphere and then hardened by quenching in oil from the above temperature to attain a hardness, Rc, of 60-65.

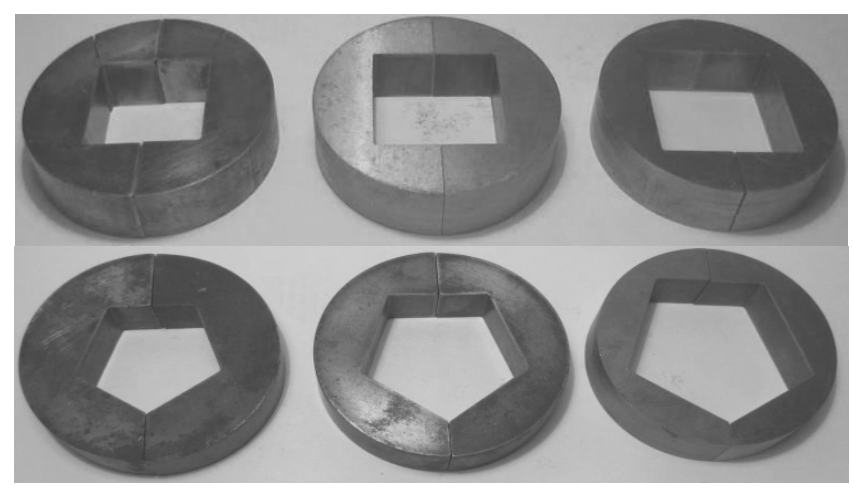

(a) Flat square and pentagon split dies.

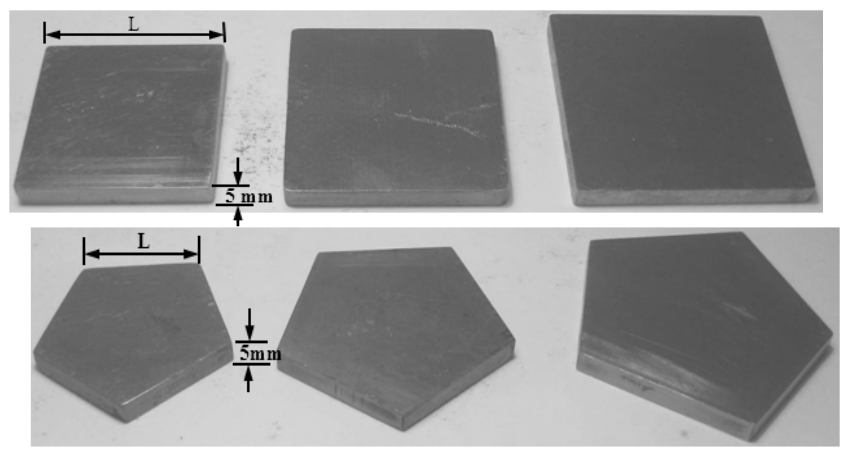

(b) Packing plates used for square and pentagon cross-section.

Fig-2: Dies of varying thickness and cross-section.

\subsection{Experimentation}

At the beginning of the tests, the die sets, the die holder and the inside faces of the extrusion chamber are cleaned with carbon tetrachloride. The two-halves of the die set are then push-fitted into the die holder and the total assembly is secured by screwing the four bolts. The full assembly is then placed on the lower table of the universal testing machine (Fig. 1). For carrying out an extrusion test, the sides of the lead specimen excepting the bottom face are smeared with grease and the specimen was placed inside the extrusion chamber. The punch is then inserted into its position. After centering the apparatus under the machine lower table, the machine is started and the extrusion process was continued. To avoid rate effect, the speed of the punch movement is adjusted to approximately $1 \mathrm{~mm} / \mathrm{min}$ and punch load is recorded at every $1 \mathrm{~mm}$ of punch travel. Extrusion is continued till the specified punch movement reaches. At this point the machine is stopped and the test is terminated. The die-punch set is de-assembled to push out the product from the die holder. Experiments are conducted for three different thicknesses $(20 \mathrm{~mm}, 15 \mathrm{~mm}$ and $10 \mathrm{~mm})$ as well as crosssections of square and pentagonal die cavity sections (Fig. 2(a)).

\section{RESULTS AND DISCUSSION}

\subsection{Variation in extrusion loads with punch travel}

The variation of punch load with punch travel as determined form the experiments and simulations for the square and pentagon section dies are shown in Fig. 3 and 4 respectively, whose peak loads are summarized and shown in in Table 1. From the figures, it is analyzed that a typical diagram consists of three principal stages. Namely (i) coining stage, in which initial compression of the billet takes place and load increases to a value called coining peak load. (ii) Steady state stage, in which there is a gradual drop in load from the coining peak load followed by gradual increase in load with increasing punch movement. (iii) The unsteady state stage, in which the load increases abruptly with small increase in pun stroke.

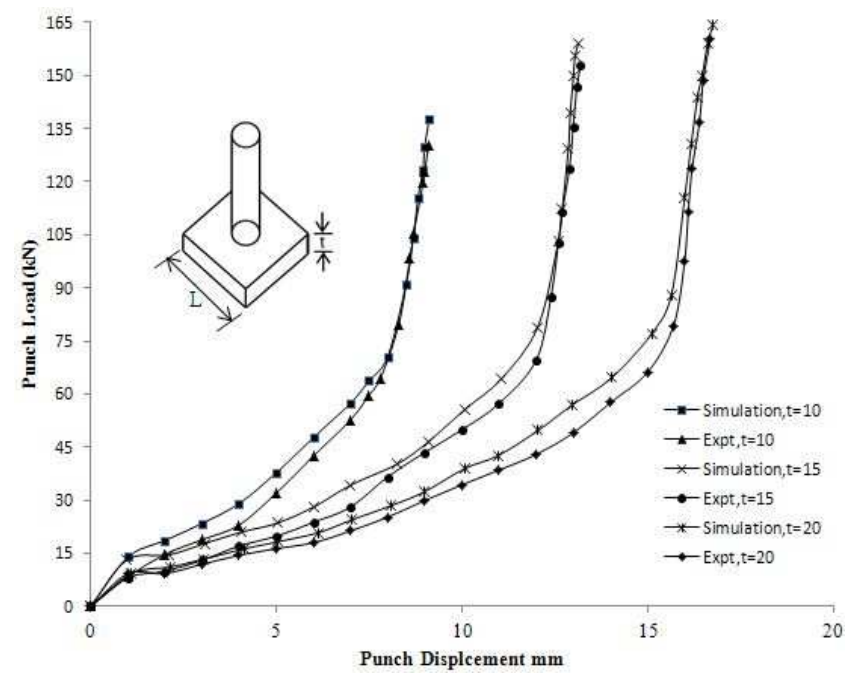

(a)Variation of punch load for $20.5 \mathrm{~mm}$ side of square head.

The drop in load in the steady state stage is due to the fact that actual lateral extrusion takes place. As the stroke increases side wise material flow begins and continues until the material reaches the die corners. Again the stroke increases, the material is forced to flow from the bottom corners towards the top corners of die cavity (Fig. 5). In this stage there is a sudden increase in load with gradual punch displacement. This load called as forming load. The forming load values increases with increase in the volume of the die cavity. This is because the surface area in contact with the metal increases, thereby increase in frictional resistance at die billet interface. It is observed that the peak load variation between experiments and FE simulation lies within $7.4 \%$ as summarized in Table 1 . 


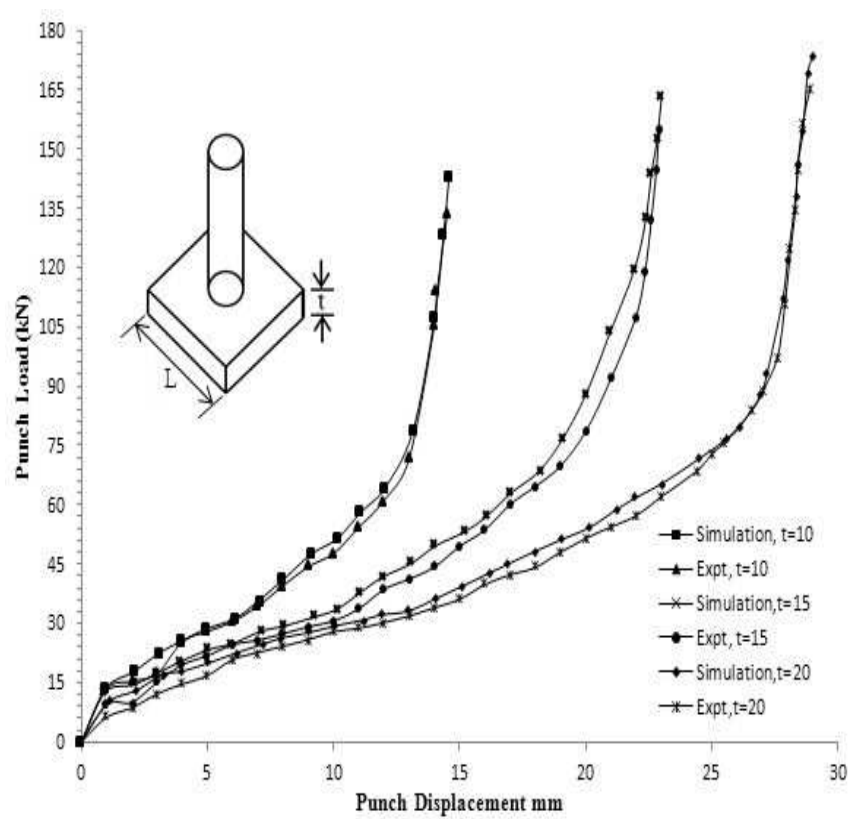

(b)Variation of punch load for $36 \mathrm{~mm}$ side of square head.

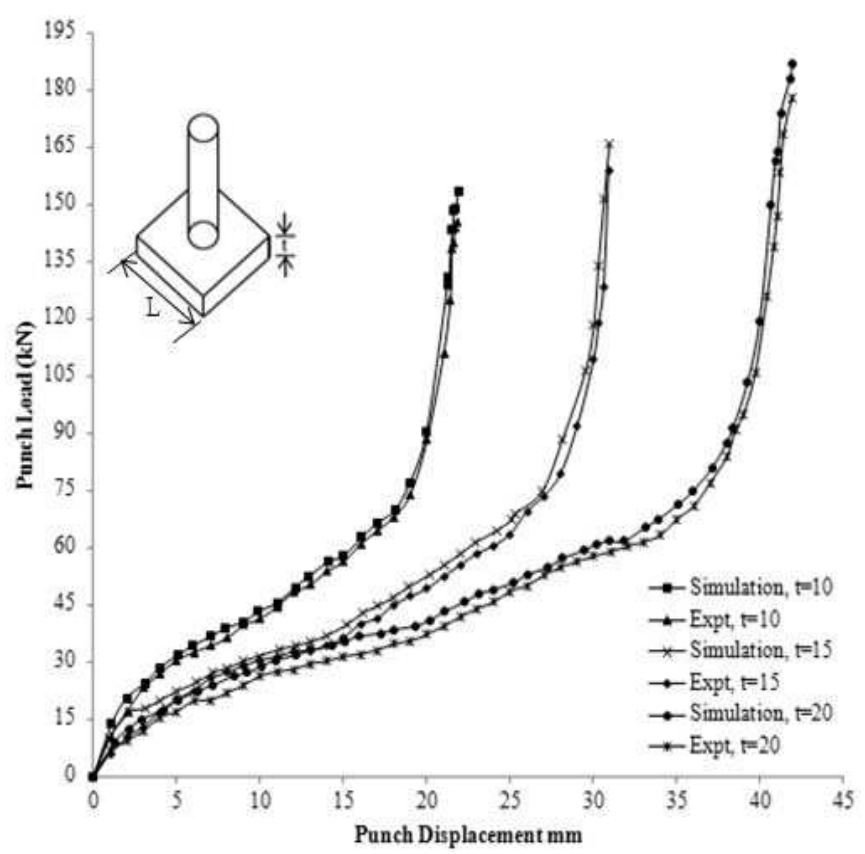

(c)Variation of punch load for $46 \mathrm{~mm}$ side of square head.

Fig-3: Variation of punch load with punch displacement for different square headed extruded product.

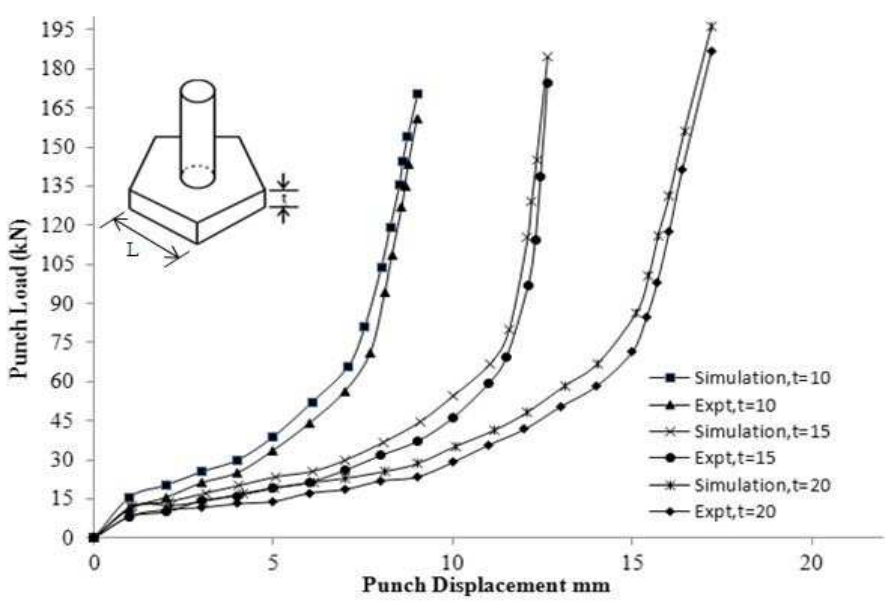

(a)Variation of punch load for $27 \mathrm{~mm}$ side of pentagonal head.

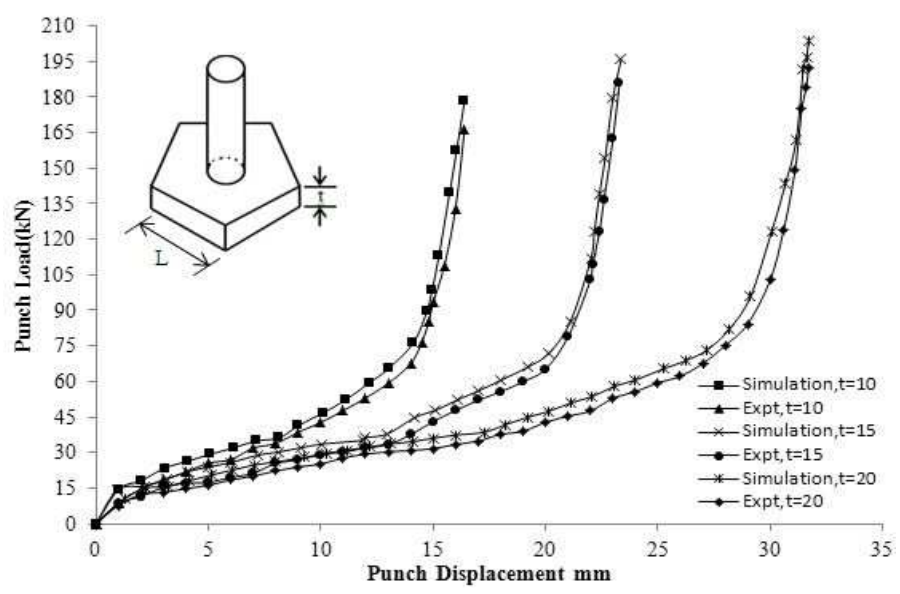

(b)Variation of punch load for $32 \mathrm{~mm}$ side of pentagonal head.

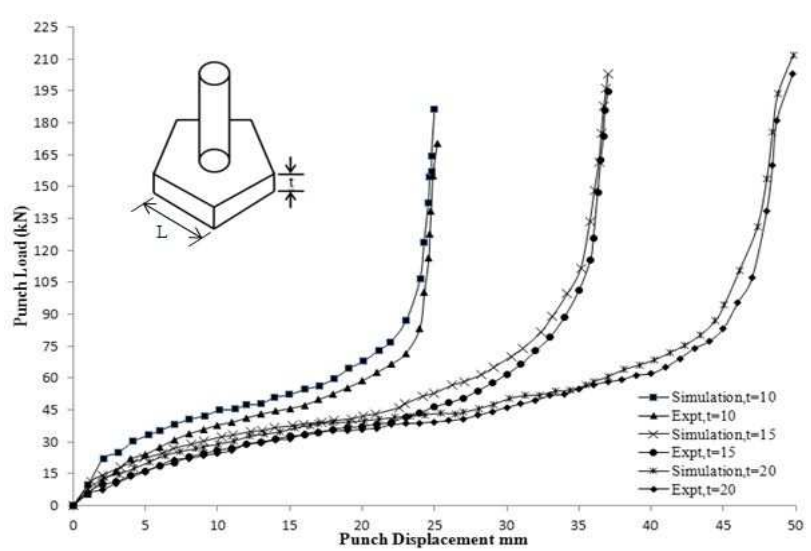

(c)Variation of punch load for $37 \mathrm{~mm}$ side of pentagonal head.

Fig-4: Variation of punch load with punch displacement for different pentagonal headed extruded product. 
Table-1: Comparison of peak loads for different extruded shapes.

\begin{tabular}{|c|c|c|c|c|}
\hline \multicolumn{5}{|c|}{ Square head with round shaft } \\
\hline $\begin{array}{l}\text { Side } \\
\text { (L), } \\
\text { mm }\end{array}$ & $\begin{array}{l}\text { Thickness } \\
(\mathrm{t}), \mathrm{mm}\end{array}$ & $\begin{array}{l}\text { Simulation } \\
\text { load }(k N)\end{array}$ & $\begin{array}{l}\text { Experiment } \\
\text { load }(\mathrm{kN})\end{array}$ & $\%$ error \\
\hline 20.5 & 10 & 137.13 & 132.20 & 3.729198 \\
\hline 20.5 & 15 & 159.16 & 152.83 & 4.141857 \\
\hline 20.5 & 20 & 164.30 & 160.30 & 2.495321 \\
\hline 36 & 10 & 142.86 & 133.10 & 7.332832 \\
\hline 36 & 15 & 162.84 & 154.85 & 5.159832 \\
\hline 36 & 20 & 173.36 & 165.32 & 4.863295 \\
\hline 46 & 10 & 153.40 & 145.16 & 5.677951 \\
\hline 46 & 15 & 165.70 & 158.65 & 4.443744 \\
\hline 46 & 20 & 187.01 & 177.90 & 5.120854 \\
\hline \multicolumn{5}{|c|}{ Pentagonal head with round shaft } \\
\hline $\begin{array}{l}\text { Side } \\
\text { (L), } \\
\mathrm{mm}\end{array}$ & $\begin{array}{l}\text { Thickness } \\
\text { (t), mm }\end{array}$ & $\begin{array}{l}\text { Simulation } \\
\text { load }(k N)\end{array}$ & $\begin{array}{l}\text { Experiment } \\
\text { load }(\mathrm{kN})\end{array}$ & $\%$ error \\
\hline 27 & 10 & 170.27 & 160.95 & 5.790618 \\
\hline 27 & 15 & 184.56 & 174.80 & 5.583524 \\
\hline 27 & 20 & 196.21 & 186.85 & 5.011507 \\
\hline 32 & 10 & 178.21 & 166.30 & 7.161756 \\
\hline 32 & 15 & 195.83 & 185.90 & 5.341581 \\
\hline 32 & 20 & 203.33 & 192.25 & 5.763329 \\
\hline 37 & 10 & 182.17 & 170.05 & 7.127315 \\
\hline 37 & 15 & 203.11 & 194.50 & 4.428278 \\
\hline 37 & 20 & 211.98 & 202.90 & 4.475111 \\
\hline
\end{tabular}

\subsection{Material flow pattern}

As an illustration, Fig. 5 shows the photograph of the flow pattern for a lateral extrusion of square and pentagon section at different punch movement for both in FEM analysis and experimental investigation. The gridlines distortion indicates that the process utilizes the maximum amount of redundant work to create the extruded product. It is also clarified that the corner filling takes place first at the bottom of the die during the steady state and then the flow proceeds towards the top corners of the die.
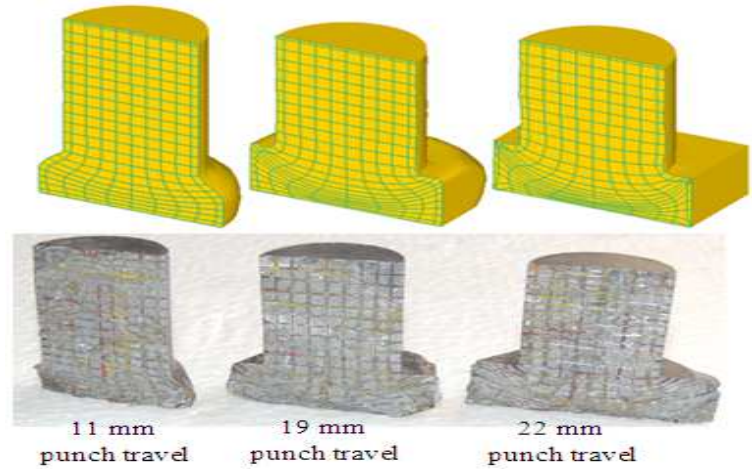

Flow patterns for square headed product.
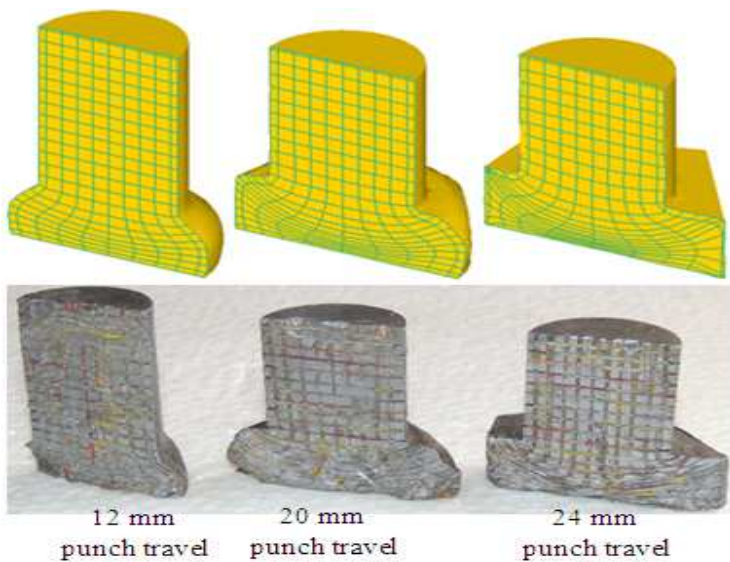

Flow patterns for pentagonal headed product.

Fig-5: Material flow pattern for different punch travel.

\subsection{Outcomes of lateral extrusion}

The photographs of the extruded square headed sections with round shaft are shown in Fig. 6. It is observed that the extruded products are fairly straight with complete corner fillings as obtained from FE-based simulation. And similar case for the pentagonal headed sections with round shaft as shown in Fig. 7.

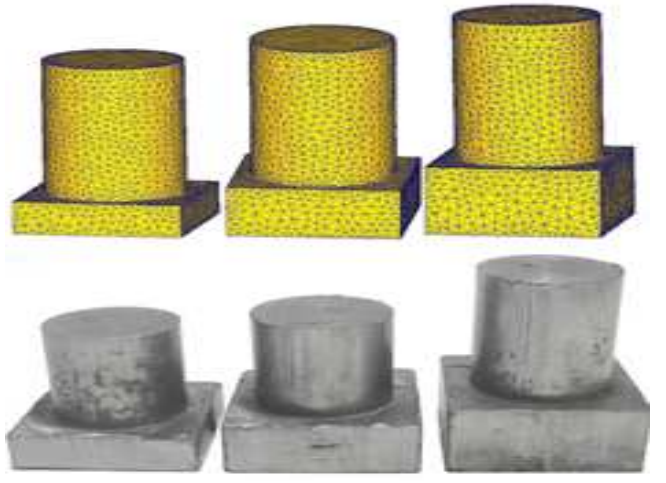

(a)Square head of $\mathrm{L}=20.5 \mathrm{~mm}$ with $\mathrm{t}=10,15$ and $20 \mathrm{~mm}$

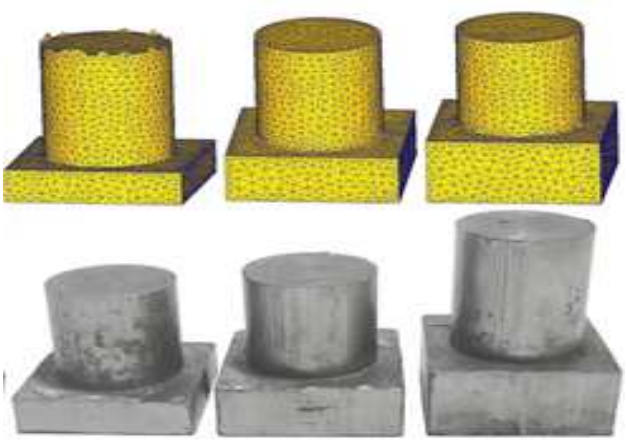

(b) Square head of $\mathrm{L}=36 \mathrm{~mm}$ with $\mathrm{t}=10,15$ and $20 \mathrm{~mm}$ 

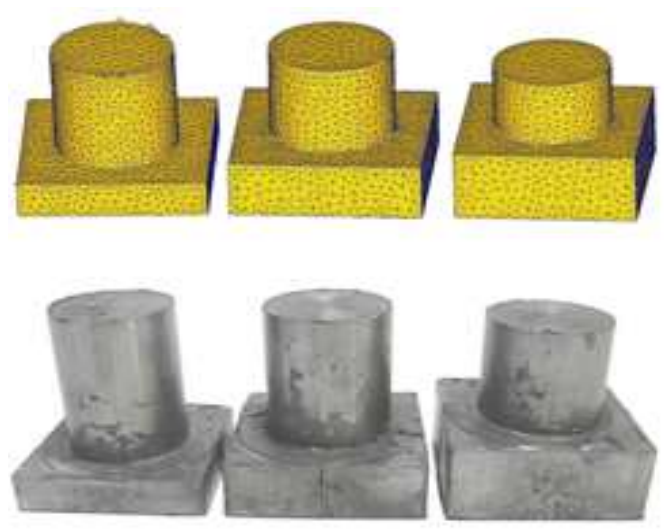

(c)Square head of $\mathrm{L}=46 \mathrm{~mm}$ with $\mathrm{t}=10,15$ and $20 \mathrm{~mm}$

Fig-6: Square headed extrude product.

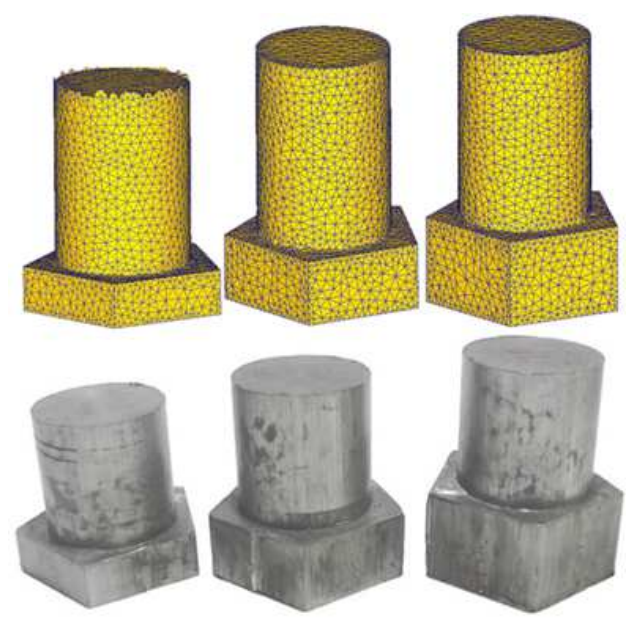

(a)Pentagonal head of $\mathrm{L}=27 \mathrm{~mm}$ with $\mathrm{t}=10,15$ and $20 \mathrm{~mm}$
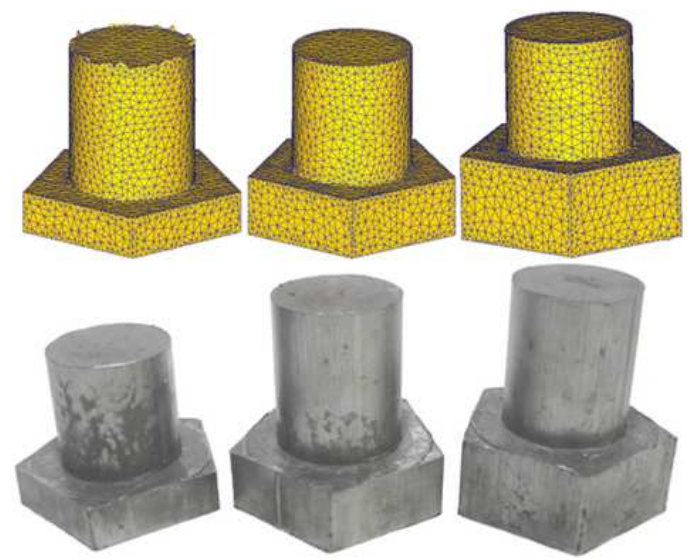

(b)Pentagonal head of $\mathrm{L}=32 \mathrm{~mm}$ with $\mathrm{t}=10,15$ and $20 \mathrm{~mm}$
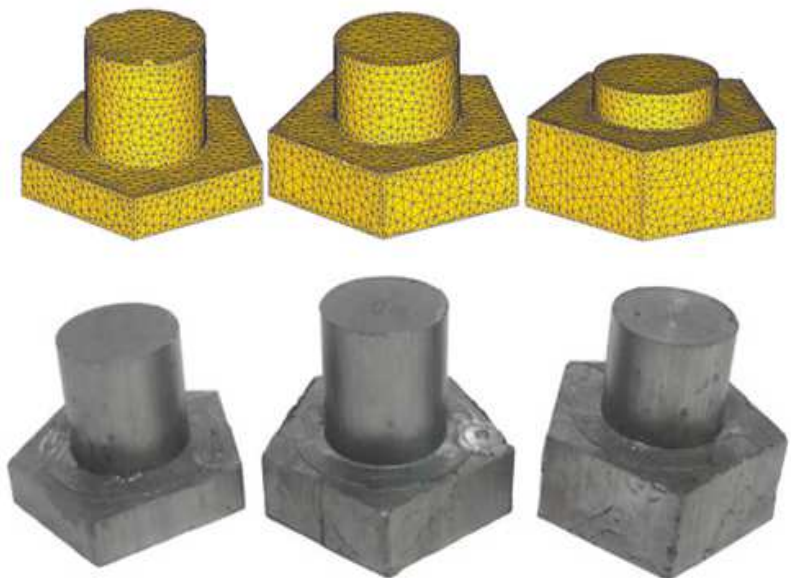

(c)Pentagonal head of $\mathrm{L}=37 \mathrm{~mm}$ with $\mathrm{t}=10,15$ and $20 \mathrm{~mm}$

Fig-7: Pentagonal headed extruded product.

\section{CONCLUSIONS}

The finite element results are compared with experimental data in terms of forming load and material flow in different regions. The simulation results qualitatively agree with the experimental results. The simulation and experimental results show the effectiveness of above mentioned parameters on the forming load and material flow. From above analysis, it is observed that with increase in the volume of die cavity, the forming load increases. It is concluded that the corner filling takes place first at the bottom of the die cavity during the steady state and then the flow proceeds towards the top corners of the die abrupt increase in load.

\section{REFERENCES:}

[1] M. Plancak, A. Brameley and F. Osman, Nonconventional cold extrusion, Journal Materials Process Technology, vol. 34, pp. 465-472, 1992.

[2] R. Balendra, Process mechanics of injection upsetting, International Journal of Machine Tools Design and Research, vol. 25(1), pp. 63-73, 1985.

[3] R. Balendra \& Y. Qin, FE simulation of the development of flaws during injection forging, International Journal of Machine Tools Manufacture, vol. 34(8), pp. 1091-1101, 1994.

[4] R. Balendra, Considerations in the Modeling of Injection Upsetting, International Journal Production Research, vol. 25(6), pp. 889-906, 1987.

[5] R. Balendra, Injection-chamber to die-cavity interface for injection forming, International Journal of Machine Tools Manufacturing, vol. 33(6), pp. 753-760, 1993.

[6] D. Y. Yang and K. J. Kim, Design of processes and products through simulation of three-dimensional extrusion, Journal of Materials Processing Technology, vol.191, pp. 2-6, 2007.

[7] R. Balendra, Yi. Qin and R. Balendra, Computer-aided design of Net-forming by injection forging of 
engineering components, Journal of Materials Processing Technology, vol. 76, pp. 62-68, 1998.

[8] R. Balendra and Y. Qin, Identification and classification of flow-dependent defects in the injection forging of solid billets, Journal of Materials Processing Technology. vol. 106, pp. 199-203, 2000.

[9] R. Balendra and Y. Qin, Injection forging: engineering and research, Journal of Materials Processing Technology, vol. 145, pp. 189-206, 2004.

[10] Y. S. Lee, S. K Hwang, Y. S. Chang and B. B. Hwang, The forming characteristics of radial-forward extrusion, Journal of Materials Processing Technology, vol.113, pp. 136-140, 2001.

[11] H. J. Choi and Hwachoi, The forming characteristics of radial-backward extrusion, Journal of Materials Processing Technology, vol. 113, pp. 141-147, 2001.

[12] L. N. Patra and S. K. Sahoo, 3D analysis of extrusionforging process: Pentagonal head with round shaft, International Journal of Applied Engineering, vol 1, PP. 2-8, 2011.

[13] U. C. Paltasingh, S. K. Sahoo, P.R. Dash, K.C. Nayak, S. Potnuru, Lateral Extrusion for Round to-Triangular Head: Experimental Studies and Three Dimensional Analyses, International Journal of Research in Aeronautical and Mechanical Engineering, vol. 1(2), pp. 1-8, 2013.

[14] N. R. Chitkara and M. A. Bhutta, Shape heading of splines and solid spur gear forms:an analysis and some experiments, International Journal of Mechanical Science, vol 43(7), pp. 1073-106, 2001.

\section{BIOGRAPHIES:}

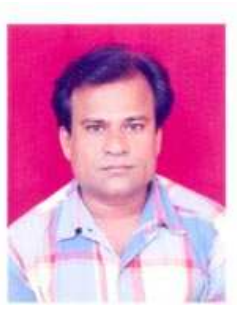

Umesh Chandra Paltasingh, Research Scholar, presently pursuing $\mathrm{Ph} \mathrm{D}$ at Sambalpur University, Burla, but performing his work at NIT, Rourkela in the field of Lateral Exclusion under the guidance of Prof. (Dr.) S. K. Sahoo, Mechanical Engg. Dept. NIT, Rourkela and Prof. (Dr.) P. R. Dash, Mechanical Engg. Department, VSSUT, Burla. He has 9 years of teaching experience in various institutes in Diploma level and 5 years of teaching experience in Degree level. Presently working as an Asst. Prof. in Mechanical Engg. Department at Padmanava Engg. College, Rourkela.

E-mail: ucpaltasingh69@gmail.com

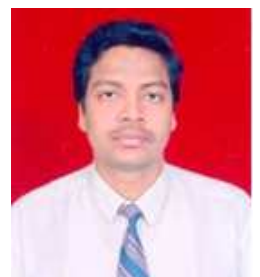

Susanta Kumar Sahoo is Professor in the Department of Mechanical Engineering, National Institute of Technology at Rourkela, India. He has completed his Post-Doc Research, 2004 Loughborough University, UK Metal Machining \& Impact Fatigue. He has both teaching and research experience of more than eighteen years in the field of Theory of Elasticity and Plasticity, Metal Forming and Laser
Forming. He has published more than sixty five papers in the International and National Journals and Conferences. He has reviewed many papers of International Journals.. He has been awarded with many Gold Medals for his Scientific Publications.

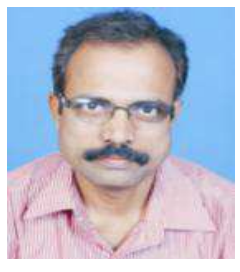

Pusparaj Dash is a Professor in the Department of Mechanical Engineering, VSSUT, Burla, India. He has published more than 20 papers in the International and National Journals and Conferences. He has reviewed many papers of International Journals.

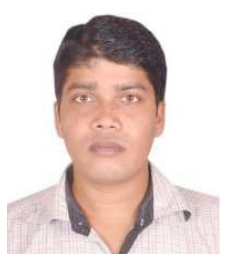

Kanhu Charan Nayak, Research Scholar, presently pursuing MTech at NIT Rourkela, performing his work at NIT, Rourkela in the field of Combined extrusion-forging under the guidance of Prof. (Dr.) S. K. Sahoo, Mechanical Engg. Dept. NIT, Rourkela. He has 4 years of teaching experience in various institutes in Degree level. 